\section{EDISON'S INVENTIONS}

THE fertility of Mr. Edison's inventive genius has frequently been referred to recently, though the attractive and popular nature of the phonograph has had the effect of throwing some almost equally important inventions into the shade. We propose, with the aid of the Scientific American, copies of which have been sent us by Mr. Edison, to draw attention to a few of these other inventions; the illustrations which we are able to give have also been kindly sent us by Mr. Edison himself. Mr. Edison's laboratory, in size and external appearance, resembles a country church. The interior, however, is not so church-like. The first apartment is a reception room, on the right of which is the private office, containing a large library of scientific works. Beyond these there is a large room containing materials and a number of glass cases filled with physical and chemical apparatus.

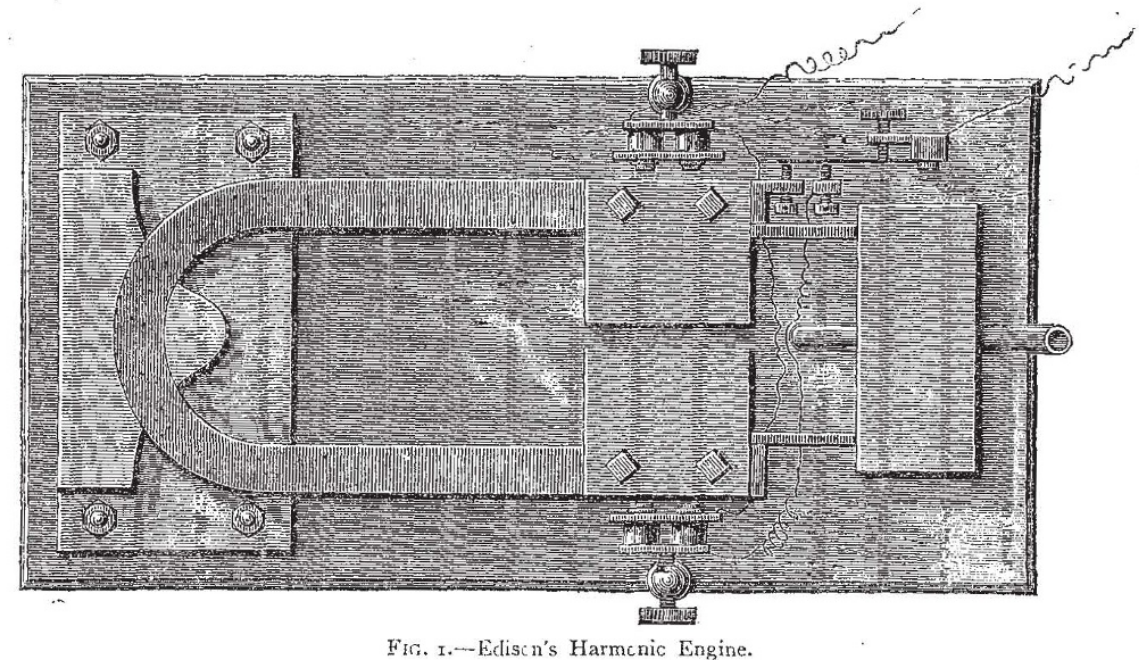

The machine shop at the rear is furnished with the best of machinery and tools, and is kept constantly in operation in carrying out the plans of Mr. Edison. On the second floor there is a single spacious room, which is the laboratory proper. Here, upon the walls, are shelves which are thickly studded with bottles, jars, and boxes, containing a multitude of substances, both common and rare. It is said to be a chronic habit of Mr. Edison to purchase every newly discovered substance, so that it will be at hand should it be required. Here also is the carbon relay, the progenitor of all existing carbon telephones, "microphones," and other instruments dependent on the changeable conductivity of carbon under a varying pressure.

One of the earlier of Mr. Edison's inventions is the electro-motograph; a telegrapbic instrument in which

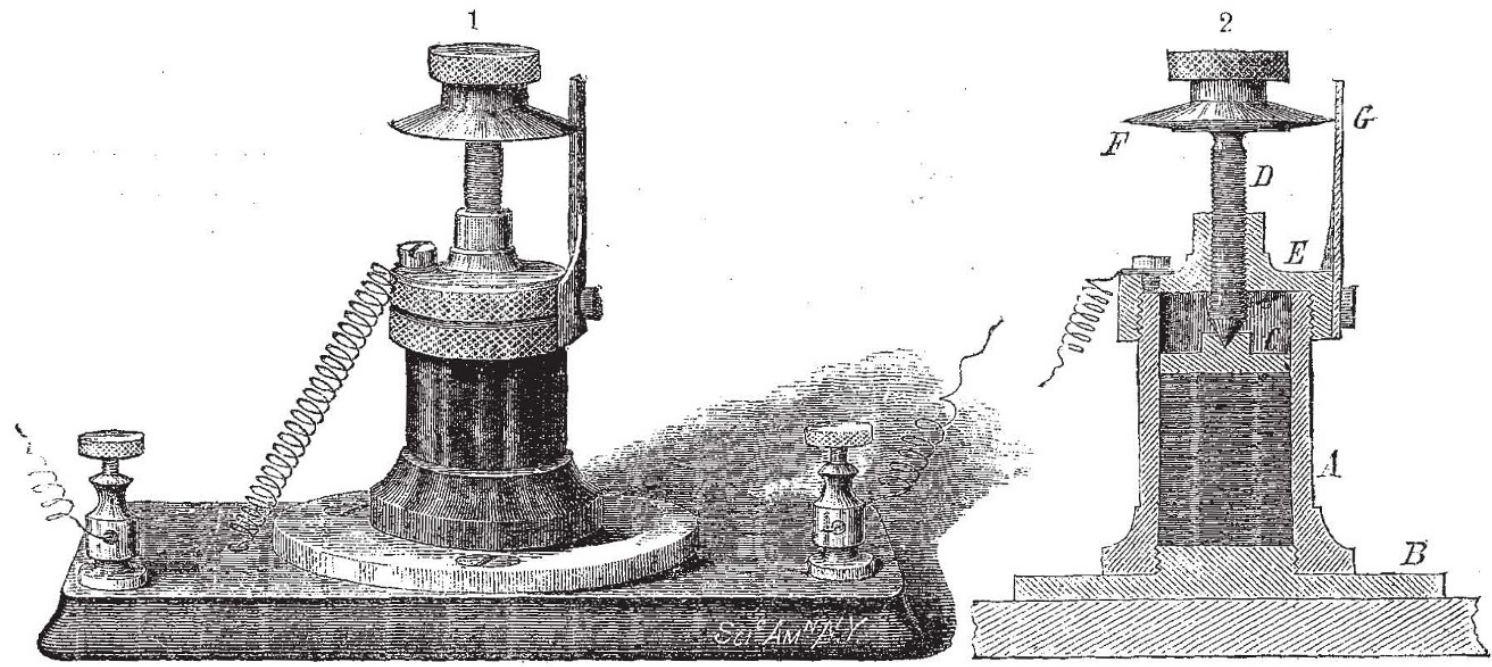

Fic. 2.-Ed.son's New Carbon Rheustat.

the sounder is operated without magnets. A strip of chemically prepared paper is laid upon a metallic surface, which is connected with one of the battery wires, and a platinum faced spring which is attached to the other battery wire is taken in the hand and pressed firmly on the paper strip; at the same time force is applied in the direction of the length of the strip. A telegraph key is placed in the electric circuit, and when the current passes through the paper the salt contained by it is instantly decomposed, so that it acts as a lubricant, permitting the spring to slide easily on the paper while the current passes, but immediately the current is broken the friction is sufficient to stop the spring.

The best solution for saturating the paper is made by dissolving $\mathrm{I} \mathrm{lb}$. of sulph. soda in I gallon of water. Any of the sodium salts will answer. 
Electricity as a motive power, until now, has been a comparative failure, as 90 per cent. of the battery has been wasted. Mr. Edison has devised a novel electrical machine which he calls the harmonic engine, in which go per cent. of the power is realised. With two small electro-magnets and three or four small battery cells, sufficient power is generated to drive a sewing machine or pump water for household purposes. This engine, which is represented in Fig. I, consists of a fork $2 \frac{1}{2}$ feet long, made of 2 -inch square steel. The curved part of the fork is firmly keyed in a solid casting which is bolted to a suitable foundation, and to each arm of the fork is secured a $35 \mathrm{lb}$. weight. Outside of and near the end of each arm is placed a very small electromagnet. These magnets are connected with each other, and with a commutator that is operated by one of the arms. The arms make thirty-fixe vibrations per second, the amplitude of which is $\frac{1}{8}$ inch. Small arms extend from the fork arms into a box containing a miniature pump having two pistons, one piston being attached to each arm. Each stroke of the pump raises a very small quantity of water, but this is compensated for by the rapidity of the strokes. Mr. Edison proposes to compress air with the harmonic engine, and use it as a motive agent for propelling sewing machines and other light machinery. The power must be taken from the fork arms so as not to affect the synchronism of their vibrations, otherwise the engine will not operate.

In quadruplex telegraphy it is vital to the working of the system to perfectly balance the electrical current. The common method of doing this is to employ a rheostat containing a great length of resistance wire, more or less of which may be thrown into or cut out of the electrical circuit by inserting or withdrawing plugs or keys. This operation often requires thirty minutes or more of time that is or might be very valuable. To remedy this difficulty

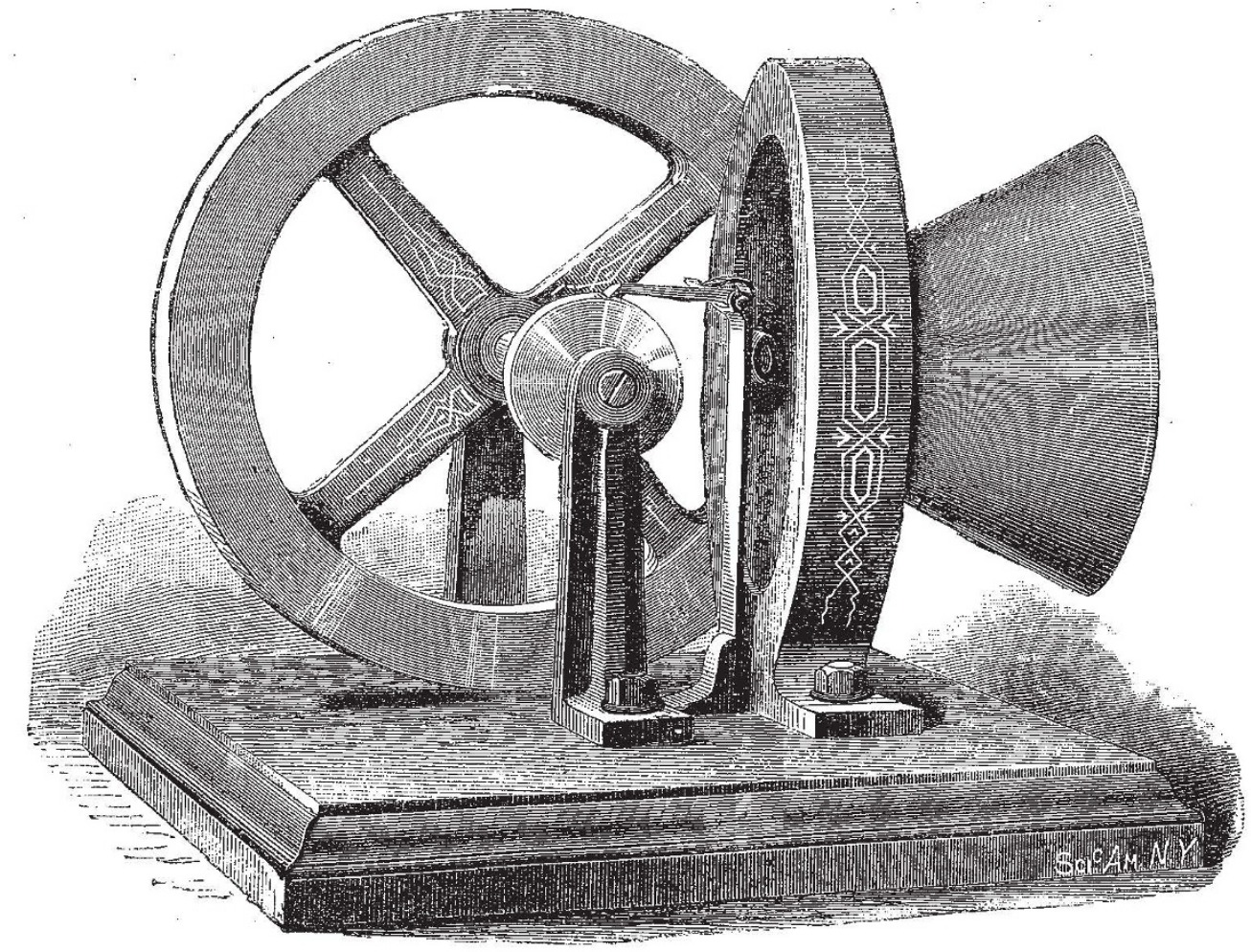

Frg. 3.-Edison's Phonomorer.

Mr. Edison has devised the instrument represented in Fig. 2 , I being a perspective view and 2 a vertical section. A hollow vulcanite cylinder $\mathrm{A}$ is screwed on a boss on the brass plate $B$. Fifty disks-cut from a piece of silk that has been saturated with sizing and well filled with fine plumbago and dried-are placed upon the boss of the plate $\mathrm{B}$, and are surmounted by a plate $\mathrm{C}$, having a central conical cavity in its upper surface. A pointed screw $D$ passes through the cap $\mathrm{E}$ at the top of the cylinder $\mathrm{A}$, and projects into the conical cavity in the plate $\mathrm{C}$. The screw is provided with a disk $\mathrm{F}$, having a knife edge periphery which extends to the scale G, and serves as an index to show the degree of compression to which the silk disks "are subjected. The instrument is placed in the circuit by connecting the cap $\mathrm{E}$ with one end of the battery wire and the plate $B$ with the other end.

The principle of the instrument is identical with that of Mr. Edison's carbon telephone. The compression of the series of disks increases conductivity; a diminutio ? of pressure increases the resistance. Any degree of resistance within the scope of the instrument may be had by turning the screw one way or the other. In this instrument the resistance may be varied from 400 to $6,000^{\circ}$ ohms, and any amount of resistance may be had by increasing the number of silk disks.

The thermo-telephone, although at present without special practical value, is certainly a novelty. It consists of a thermopile having placed in its collecting funnel a hard rubber disc. A sound made in front of this disc is heard in a receiving telephone connected with the thermopile.

The rationale of this is at once apparent when a strip of hard rubber is placed against the lips and bent, so that the strip will be alternately concave and convex. The difference in temperature is very perceptible, the convex surface being cold and the concave surface warm, and, however rapid the vibrations which render the surfaces alternately convex and concave, the result is the same. 
Mr. Edison, in his telephone and phonograph experiments, discovered that the vibrations of the vocal chords were capable of producing considerable mechanical effect. Acting on this hint, he began experiments on a phonometer, or instrument for measuring the mechanical force of sound-waves produced by the human yoice. In the course of these experiments he constructed the machine shown in Fig. 3, which exhibits the dynamic force of the voice. The machine has a diaphragm and mouth-piece similar to a phonograph. A spring which is secured to the bed piece rests on a piece of rubber tubing placed against the diaphragm. This spring carries a pawl that acts on a ratchet or roughened wheel on the fly-wheel shaft. A sound made in the mouth-piece creates vibrations in the diaphragm, which are sufficient to propel the fly-wheel with considerable velocity. It requires a surprising amount of pressure on the fly-wheel shaft to stop the machine while a continuous sound is made in the mouthpiece.

The speaking trumpet, which, for two centuries at least, has been employed to direct sound so that it may be heard over a long distance, is much used at sea, and is often employed on land to direct vocal sounds so that they may be heard above other sounds. It is tolerably certain that the speaking trumpet is of modern origin, and that it is the invention of Samuel Moreland, 1670 .

Kircher, in his "Ars Magna et Umbra" and in his "Phonurgia," mentions a kind of gigantic speakingtrumpet, described as the horn of Alexander. According to Kircher, this horn enabled Alexander the Great to all his soldiers from a distance of ten miles. The diameter of the ring must have been eight feet, and Kircher conjectures that it was mounted on three poles.

Late in the last century Prof. Huth, a German, made a model of the horn, and found that it served as a powerful speaking-trumpet, but we are considerably in doubt as to the distance through which sounds can be projected through such an instrument.

The ear-trumpet, which is the counterpart of the speaking-trumpet, has been made in various forms during the last two centuries, but no form yet devised has any

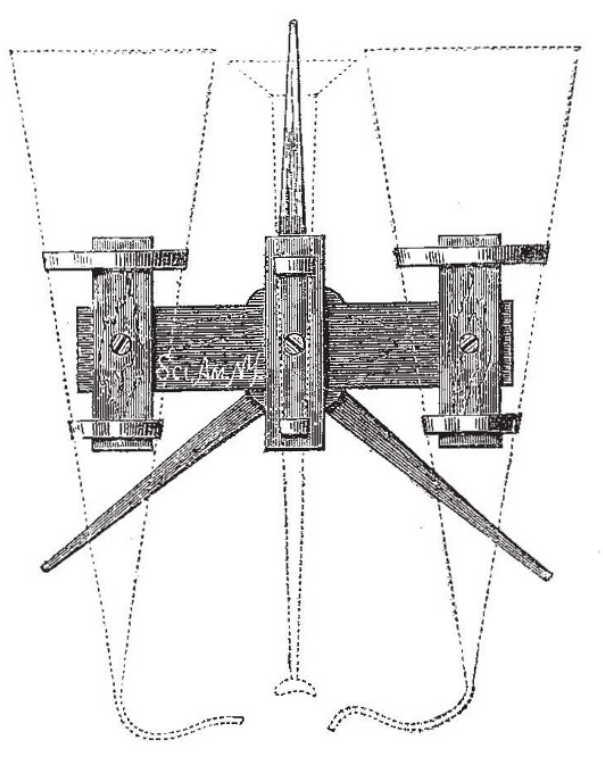

Fig. 4.-Plan of Megaphone.

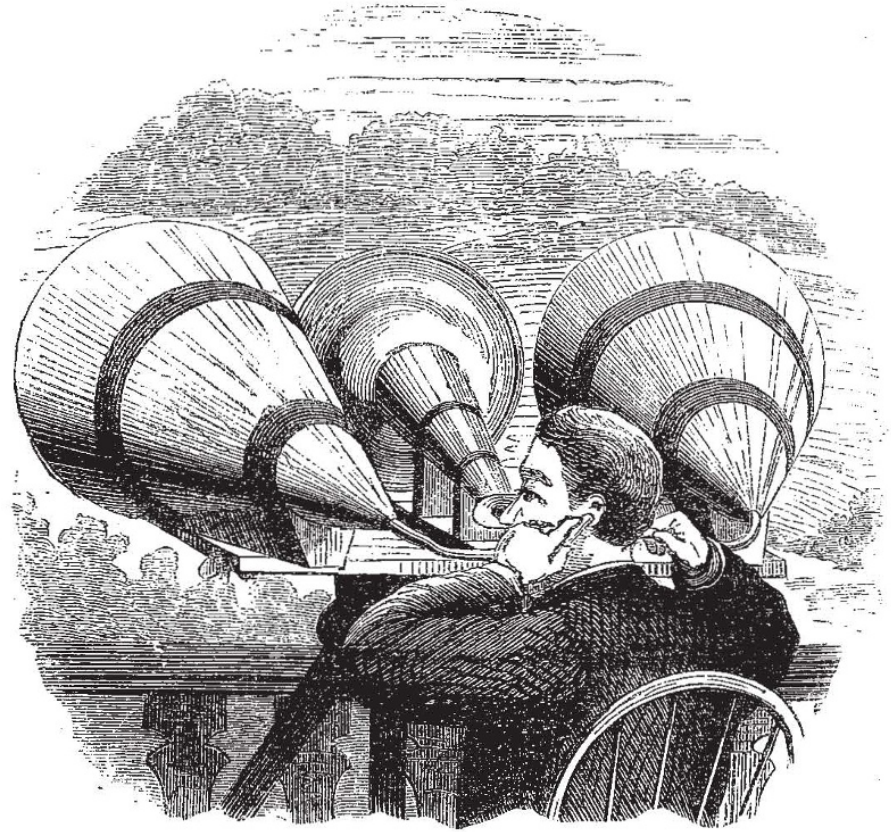

FIG. 5.--Edison's Megaph sne. advantage over a plain conical tube with a bell-sbaped or flaring mouth.

Mr. Edison, in his researches on sound, has made many curious experiments, one of the most interesting of which is that of conversing through a distance of $1 \frac{1}{2}$ to 2 miles with no other apparatus than a few paper funnels. These funnels constitute the megaphone, an instrument wonderful both for its simplicity and effectiveness. In the plan, Fig. 4, the details of construction are clearly shown, and Fig. 5 represents the instrument as it stands on the balcony of Mr. Edison's laboratory. A mile and a half distant there is another instrument exactly like the one in Fig. 5 .

The two larger funnels are 6 feet 8 inches long and $27 \frac{1}{2}$ inches in diameter at the larger end. These funnels are each provided with a flexible ear-tube, the end of which is placed in the ear. The speaking-trumpet in the middle does not differ materially from the ordinary ones. It is a little longer and has a larger bell mouth. With this instrument conversation can be readily carried on through a distance of $1 \frac{1}{2}$ to 2 miles. A low whisper, uttered with- out using the speaking-trumpet, is distinctly audible at a thousand feet, and walking through grass and weeds may be heard at a much greater distance.

These statements, it must be understood, are given on the authority of the Scientific American, but some experiments lately made with a paper megaphone by Prof. Barrett lend them strong support

\section{COLOUR BLINDNESS IN RELATION TO THE HOMERIC EXPRESSIONS FOR COLOUR}

I $N$ an article on "The Colour Sense" in the number of the Nineteenth Century for October last, Mr. Gladstone points out certain peculiarities, very remarkable and very difficult to account for, in the expressions for colour used by Homer. "Although," he says, "this writer has used light in its various forms for his purposes with perhaps greater splendour and effect than any other poet, yet the colour adjectives and colour descriptions of the poems are not only imperiect but highly 